Service social

Présentation du numéro

Identité et construction de soi chez les garçons et les hommes

\title{
Michel Dorais
}

Volume 58, numéro 1, 2012

URI : https://id.erudit.org/iderudit/1010393ar

DOI : https://doi.org/10.7202/1010393ar

Aller au sommaire du numéro

\section{Éditeur(s)}

École de service social de l’Université Laval

ISSN

1708-1734 (numérique)

Découvrir la revue

Citer ce document

Dorais, M. (2012). Présentation du numéro : identité et construction de soi chez les garçons et les hommes. Service social, 58(1).

https://doi.org/10.7202/1010393ar 


\section{Présentation du numéro}

\section{Identité et construction de soi chez les garçons et les hommes}

Le présent numéro est né du colloque international Perspectives futures en intervention, politique et recherche sur les hommes et les masculinités, lequel s'est tenu en mars 2011 à I'Université Laval. Nombreuses étaient les présentations portant sur la construction de soi des garçons et des hommes et, de façon plus générale, sur l'identité masculine, d'où l'idée d'y consacrer un numéro de la revue Service social. Des articles nous sont aussi parvenus d'ailleurs, participant à étoffer ce numéro de contributions novatrices. En effet, la condition masculine et ses aléas ont longtemps été des réalités négligées dans le monde de la recherche et de l'intervention sociale. On ne peut que se réjouir que, depuis une ou deux décennies, des chercheuses et des chercheurs, à bon droit inspirés par la recherche sur les femmes, se soient plus que jamais questionnés sur des problématiques particulières aux garçons et aux hommes. Leurs études ont souvent permis de mieux soutenir les intervenants sociaux dans leur travail et, pour paraphraser le très beau titre d'un ouvrage pionnier de Germain Dulac, rappelé qu'il faut Aider les hommes... aussi.

En terminant, merci à Gilles Tremblay, organisateur du colloque et directeur de l'équipe de recherche Masculinités et Société, qui a encouragé plusieurs de ses conférenciers et conférencières à soumettre à notre revue un texte issu de leurs conférences respectives.

Michel Dorais, professeur titulaire

Directeur, revue Service social 